\title{
Comparison of the effects of atenolol, sotalol and labetalol on muscle blood flow in man
}

\author{
G. Venkat Raman, F.M. Mwongera and D.J. Warren \\ Hypertension Laboratory, Department of Renal Medicine, University of Southampton, St. Mary's Hospital, \\ Portsmouth PO3 6AD, UK.
}

\begin{abstract}
Summary: A double-blind study of the effect of three beta-adrenoceptor blocking drugs (betablockers) on exercise muscle blood flow (MBF) in 14 normotensive volunteers was carried out. MBF was measured by the xenon-133 clearance technique. MBF was not altered by placebo, sotalol or labetalol. Atenolol significantly reduced MBF compared with placebo, sotalol and labetalol.

We conclude that sotalol and labetalol may be more useful than conventional beta-blockers for treatment of hypertension or angina in association with peripheral vascular disease.
\end{abstract}

\section{Introduction}

Beta-blockers are widely used for treatment of hypertension and angina pectoris. Peripheral blood flow may be significantly reduced by many of these drugs (McSorley \& Warren, 1978; Vale et al., 1977; Rees, 1979; Gokal et al., 1979). Both selective and nonselective beta-blockers reduce muscle blood flow (MBF), but our studies suggest that partial agonist activity may confer partial protection against this unwanted side effect (Smith \& Warren, 1982). In patients with intermittent claudication MBF during exercise was shown to fall by about $30 \%$ after two weeks treatment with propranolol, pindolol and atenolol (Smith \& Warren, 1981). We have examined the acute effects of two beta-blockers with additional properties which suggest that they may have less adverse effects on MBF. Labetalol has an alphaadrenoceptor blocking action which may ameliorate the reduction in MBF which follows pure beta blockade. Sotalol may have less negative inotropic effect on the heart than other beta-blockers and thus may have a smaller effect on peripheral circulation (Brooks et al., 1970). We have compared the effects on MBF of labetalol, sotalol, atenolol and placebo.

\section{Patients and methods}

Fourteen healthy normotensive non-smoking male volunteers were studied: age $35( \pm 5.8)$ years, weight $73.4( \pm 7.7) \mathrm{kg}$. We studied the effects of a single oral

Correspondence: G. Venkat Raman M.D., M.R.C.P., St. Mary's Hospital, Portsmouth PO3 6AD

Accepted: 15 April 1986 dose of atenolol $100 \mathrm{mg}$, labetalol $200 \mathrm{mg}$, sotalol $160 \mathrm{mg}$ or placebo (ascorbic acid $50 \mathrm{mg}$ ) on heart rate, blood pressure and MBF before and 2, 4, and 6 hours after dosing. These doses were chosen as standard doses used for treatment of hypertension. The drugs were given in random order on different study days, in opaque gelatine capsules of identical appearance, with $200 \mathrm{ml}$ of water. Different drugs were studied on separate occasions at intervals of not less than 7 days. The subjects were rested supine for a period of 15 minutes and blood pressure and heart rate were recorded every 3 minutes using Sentron ${ }^{\circledR}$ automatic blood monitor (CR Bard Inc., Illinois, USA). Xenon$133(0.1 \mathrm{mCi}$ in $0.1 \mathrm{ml}$ of normal saline) was injected into the tibialis anterior muscle $10 \mathrm{~cm}$ below the tibial tuberosity and $2 \mathrm{~cm}$ lateral to the anterior edge of the tibia, using a fine needle ( 25 gauge $16 \mathrm{~mm}$ ), with the patient resting. A cadmium telluride detector was strapped to the skin over the site of the injection and radioactivity measured using a small solidstate counter with memory (Memolog, Vertec Scientific, Slough, Bucks, England). The exercise was standardized to 5 minutes walking on a treadmill at $3 \mathrm{~km} / \mathrm{h}$ against a $10 \%$ gradient. Immediately at the end of exercise heart rate and blood pressure were recorded standing. MBF was calculated from the slope of the xenon clearance curve during exercise as described earlier (Smith et al., 1981; Lassen et al., 1964; Clausen \& Lassen, 1971). Ten $\mathrm{ml}$ of blood was taken just before exercise during each of the four observation periods for estimation of drug concentration. Calculated MBF is expressed as $\mathrm{ml} / 100 \mathrm{~g} / \mathrm{min}$. Values were compared by the Students' paired $t$ test. 
Table I Heart rate and mean arterial pressure after beta-blockers

\begin{tabular}{|c|c|c|c|c|c|c|c|c|}
\hline \multirow{2}{*}{$\begin{array}{l}\text { Time } \\
\text { (hours) }\end{array}$} & \multicolumn{2}{|c|}{ Atenolol } & \multicolumn{2}{|c|}{ Sotalol } & \multicolumn{2}{|c|}{ Labetalol } & \multicolumn{2}{|c|}{ Placebo } \\
\hline & $H R$ & $M A P$ & $H R$ & $M A P$ & $H R$ & $M A P$ & $H R$ & $M A P$ \\
\hline 0 & $68 \pm 8.6$ & $90 \pm 7.7$ & $67 \pm 10$ & $87 \pm 7.1$ & $70 \pm 10.8$ & $89 \pm 5.9$ & $70 \pm 11.3$ & $91 \pm 10.4$ \\
\hline 2 & $* 56 \pm 7.3$ & $* 83 \pm 7.4$ & $* 56 \pm 8.2$ & $* 83 \pm 7.6$ & $64 \pm 8.5$ & $* 84 \pm 5.3$ & $66 \pm 9.6$ & $88 \pm 7.2$ \\
\hline 4 & $* 60 \pm 7$ & $* 82 \pm 7.4$ & $* 60 \pm 8.3$ & $* 81 \pm 6$ & $69 \pm 7.3$ & $85 \pm 5.6$ & $69 \pm 10$ & $87 \pm 7.4$ \\
\hline 6 & $* 57 \pm 7.4$ & $* 79 \pm 8.3$ & $* 58 \pm 5$ & $* 80 \pm 6.7$ & $66 \pm 10.6$ & $* 83 \pm 5.5$ & $65 \pm 11.4$ & $87 \pm 8.8$ \\
\hline
\end{tabular}

$\mathrm{HR}=$ Heart rate (beats/min); MAP = mean arterial pressure $(\mathrm{mmHg})$. Results expressed as mean \pm standard deviation; $* P<0.05$.

\section{Results}

Supine heart rate and mean arterial pressure measurements are shown in Table I, post-exercise values in Table II, and plasma levels of the drugs in Table III. There was a significant fall in heart rate after sotalol and atenolol, but not after labetalol or placebo. Mean arterial pressure, systolic and diastolic blood pressures fell significantly after all the three active drugs, when compared with placebo. For the sake of brevity we have omitted systolic and diastolic blood pressures. There were no significant differences in exercise MBF (Table IV) at time 0 on the four study days, measurements being in the range of $18.7-20.1 \mathrm{ml} / 100 \mathrm{~g} / \mathrm{min}$. After administration of sotalol, labetalol and placebo there was no significant change in MBF at 2, 4 or 6 hours, or when the latter three values were averaged. After administration of atenolol the mean exercise MBF fell at 2 hours to $17.2 \mathrm{ml} / 100 \mathrm{~g} / \mathrm{min}$, remained at that value at 4 hours and fell further at 6 hours to $15.7 \mathrm{ml} / 100 \mathrm{~g} / \mathrm{min}$
$(P<0.05)$. The 6 hour post-atenolol MBF was also significantly less than the corresponding 6 hour postlabetalol value of $20.8 \mathrm{ml} / 100 \mathrm{~g} / \mathrm{min}(P<0.05)$. The average of the 2,4 and 6 hour values after atenolol was $16.7 \mathrm{ml} / 100 \mathrm{~g} / \mathrm{min}$ and this was again significantly less than the baseline value $(P<0.05)$. Further, when the 2, 4 and 6 hour values were pooled and compared, the post-atenolol $\mathrm{MBF}$ was significantly less than that of sotalol $(P<0.05)$, labetalol $(P<0.01)$ and placebo $(P<0.01)$. There were no differences in the corresponding values between sotalol, labetalol and placebo.

\section{Discussion}

Hypertension and ischaemic heart disease frequently occur in association with peripheral vascular disease. Beta-blockers are widely used in the treatment of hypertension and angina but their use may often be limited by precipitation or aggravation of peripheral

Table II Post-exercise heart rate and mean arterial pressure after beta-blockers

\begin{tabular}{lcccccccc}
\hline $\begin{array}{l}\text { Time } \\
\text { (hours) }\end{array}$ & \multicolumn{2}{c}{ Atenolol } & \multicolumn{2}{c}{ Sotalol } & \multicolumn{2}{c}{ Labetalol } & \multicolumn{2}{c}{ Placebo } \\
\hline 0 & \multicolumn{1}{c}{ MAP } & \multicolumn{1}{c}{ HR } & MAP & HR & MAP & HR & MAP \\
\hline 2 & $92 \pm 11$ & $95 \pm 8$ & $96 \pm 13$ & $93 \pm 9$ & $101 \pm 19$ & $94 \pm 13$ & $98 \pm 19$ & $96 \pm 15$ \\
4 & $* 65 \pm 3$ & $86 \pm 6$ & $* 75 \pm 11$ & $88 \pm 8$ & $92 \pm 7$ & $85 \pm 9$ & $93 \pm 12$ & $88 \pm 15$ \\
6 & $* 70 \pm 2$ & $* 81 \pm 5$ & $* 77 \pm 5$ & $* 84 \pm 6$ & $93 \pm 10$ & $* 87 \pm 12$ & $94 \pm 13$ & $94 \pm 9$ \\
\hline & $* 70 \pm 9$ & $* 81 \pm 8$ & $* 79 \pm 9$ & $* 84 \pm 10$ & $* 89 \pm 12$ & $* 90 \pm 7$ & $96 \pm 19$ & $95 \pm 13$ \\
\hline
\end{tabular}

†see Table I; ${ }^{*} P<0.05$. 
Table III Plasma drug levels of beta-blockers (ng/ml)

\begin{tabular}{lccc}
\hline $\begin{array}{l}\text { Time } \\
\text { (hours) }\end{array}$ & Atenolol & Sotalol & Labetalol \\
\hline 0 & ND & ND & ND \\
2 & $534 \pm 194$ & $970 \pm 239$ & $40 \pm 10$ \\
4 & $518 \pm 130$ & $868 \pm 315$ & $21 \pm 8$ \\
6 & $377 \pm 100$ & $653 \pm 224$ & $13 \pm 4$ \\
\hline
\end{tabular}

$\mathrm{ND}=$ not detected

vascular disease. Though peripheral vascular insufficiency has been clearly associated with beta-blockers in contrast to methyl dopa (Marshall et al., 1976) formal measurements of blood flow have not been well studied. In an attempt to identify beta-blockers without this adverse effect we decided to study the effect on MBF of two agents with unusual properties and compare them with placebo and atenolol. The latter drug has been shown to reduce MBF in normal subjects (Smith \& Warren, 1982) and claudicants (Smith \& Warren, 1981), and this effect has been confirmed in this study. All three active drugs produced the expected reduction in blood pressure. Sotalol and atenolol reduced heart rate but labetalol did not.

One of the mechanisms by which non-selective betablockers may reduce MBF is thought to be unopposed stimulation of alpha-receptors in the presence of beta blockade. Labetalol possesses additional alpha-adrenoceptor blocking actions and this would explain the lack of effect of this drug on MBF or heart rate. Unlike other beta-blockers labetalol is not known to cause peripheral skin necrosis (Rees, 1979; Gokal et al., 1979). Indeed, it has been demonstrated that after chronic treatment labetalol preserves finger blood flow better than propranolol but not atenolol, in hypertensive patients without peripheral vascular disease (van der Veur et al., 1985).

Sotalol is a beta-blocker that has been shown to have Class III anti-arrhythmic properties (Edvardsson et al., 1980), and may have less effect than other betablockers on cardiac output (Brooks et al., 1970), though this is disputed (Verniory et al., 1976; Wendelin et al., 1974; Dexter et al., 1974). Its effect on peripheral vascular disease is not established and our studies suggest that it does not have any adverse effect on MBF. Nevertheless this lack of effect is not clearly explained and merits further investigation.

We conclude that this lack of effect of sotalol and labetalol on muscle blood flow could be of significant benefit to the patient suffering from a combination of peripheral vascular disease and angina or hypertension.

\section{Acknowledgements}

We thank Mrs J. Collett, S.R.N., Research Sister, for helping with the study and Mrs Joyce Turk and Mrs Tracey Messer for typing the manuscript. This study was supported by a grant from Bristol-Myers Cardiovascular.

Table IV Exercise muscle blood flow $\dagger$ after beta-blockers

\begin{tabular}{lcccc}
\hline $\begin{array}{l}\text { Time } \\
\text { (hours) }\end{array}$ & Atenolol & Sotalol & Labetalol & Placebo \\
\hline 0 & $19.1 \pm 5.3$ & $19.9 \pm 5.1$ & $20.1 \pm 5.8$ & $18.7 \pm 4.2$ \\
2 & $17.2 \pm 6.8$ & $20.4 \pm 6.9$ & $20.5 \pm 7.7$ & $19.1 \pm 5.7$ \\
4 & $17.2 \pm 6.4$ & $19.9 \pm 7.1$ & $19.4 \pm 5.4$ & $20.8 \pm 7.1$ \\
6 & $* 15.7 \pm 5.3$ & $18.2 \pm 5.2$ & $20.8 \pm 5.4$ & $20.0 \pm 6.6$ \\
$\begin{array}{l}\text { Mean of } 2, \\
4,6\end{array}$ & $* 16.7 \pm 6.1$ & $19.5 \pm 6.4$ & $20.2 \pm 6.1$ & $20.0 \pm 6.4$ \\
\hline
\end{tabular}

$\left\lceil\mathrm{ml} / 100 \mathrm{~g} / \mathrm{min}\right.$ (mean \pm s.d.); ${ }^{*} P<0.05$. 


\section{References}

BROOKS, H., BANAS, J., MEISTER, S., SZUCS, M., DALEN, J. \& DEXTER, L. (1970). Sotalol-induced beta blockade in cardiac patients. Circulation, 42, 99.

CLAUSEN, J.P. \& LASSEN, N.A. (1971). Muscle blood flow during exercise in normal man studied by 133 -xenon clearance method. Cardiovascular Research, 5, 245.

DEXTER, L., BROOKS, H., BANAS, S.J., MEISTER, S., SZUCS, M.M. \& DALEN, J.E. (1974). Effects of sotalol on myocardial function in dogs and in patients with heart failure. Excerpta Medica International Symposium, Rome, I-41-55. EDVARDSSON, N., HIRSCH, I., EMANUELSSON, H., PONTEN, J. \& OLSSON, S.B. (1980). Sotalol-induced delayed ventricular repolarization in man. European Heart Journal, 1, 335.

GOKAL, R., DORNAN, T.L. Y LEDINGHAM, J.G.G. (1979). Peripheral skin necrosis complicating beta blockade. British Medical Journal, 1, 721.

LASSEN, N.A., LINDBJERG, J. \& MUNCK, O. (1964). Measurement of muscle blood flow through skeletal muscle by intramuscular injection of 133-Xenon. Lancet, $i$, 868.

MCSORLEY, P. \& WARREN, D.J. (1978). Effects of propranolol and metoprolol on the peripheral circulation. British Medical Journal, 2, 1598.

MARSHALL, A.J., ROBERTS, C.J.C. \& BARRITT, D.W. (1976). Raynaud's phenomenon as side effect of beta blockers in hypertension. British Medical Journal, 1, 1498.
REES, P.J. (1979). Peripheral skin necrosis complicating beta blockade. British Medical Journal, 1, 955.

SMITH, R.S. \& WARREN, D.J. (1981). Effect of beta-blocking drugs on peripheral blood flow in intermittent claudication. Journal of Cardiovascular Pharmacology, 4, 2.

SMITH, R.S., BOJSEN, J. \& WARREN, D.J. (1981). Assessment of cadmium telluride detector system for measurement of muscle blood flow during dynamic exercise in man. Cardiovascular Research, 12, 731 .

SMITH, R.S. \& WARREN, D.J. (1982). Effect of acute oral beta adrenergic blockade on muscle blood flow in man. Cardiovascular Research, 16, 205.

VALE, J.A. DE PETTE, S.J. \& PRICE, T.M. (1977). Peripheral gangrene complicating beta blockade. Lancet, ii, 412 .

VAN DER VEUR, E., TEN BERGE, B.S., WOUDA, A.A. \& WESSELING, H. (1985). Effects of atenolol, labetalol and propranolol on the peripheral circulation in hypertensive patients without obstructive vascular disease. European Journal of Clinical Pharmacology, 28, 131.

VERNIORY, A., STAROUKINE, M., DELWICHE, F. \& TELERMAN, M. (1976). Effect of sotalol on haemodynamics and renin-angiotensin-aldosterone system in hypertensive patients. Clinical Science and Molecular Medicine, 51, 9.

WENDELIN, H., SUNDQUIST, H. \& ARSTILA, M. (1974). Sotalol in angina patients. Excerpta Medica International Symposium, Rome, I-56-62. 